\title{
RISING TO THE CLIMATE CHALLENGE
}

\author{
Murray Smith ${ }^{1}$
}

\begin{abstract}
Agriculture dominates economic activity within Australia’s Murray-Darling Basin, with 41 percent $^{\mathrm{i}}$ of Australia's gross value of agricultural production ${ }^{\mathrm{ii}}$ generated from the basin and about two-thirds of this total production exported ${ }^{\text {iii }}$. Historically low rainfall has resulted in cutbacks in irrigator water allocations, urban water restrictions and reduced environmental flows.

A key element of the Victorian Government's response to water scarcity has been to establish the Northern Victoria Irrigation Renewal Project (NVIRP) to plan, design and deliver a program of works that will modernize the Goulburn Murray Irrigation District (GMID). NVIRP is being funded by the State Government \$600M AUS, urban water users \$300M AUS, GMID water users \$100M AUS and Australian Commonwealth Government $\$ 1$ billion AUS.

Modernization of the GMID irrigation distribution system will increase the standard of water delivery service to its customers, providing near-on-demand water delivery onfarm and a better managed delivery system for operator Goulburn-Murray Water. The project will reduce system losses (currently 780 to 870 GL per annum on average) and is anticipated to generate up to $425 \mathrm{GL}$ of long term average annual water savings.
\end{abstract}

This paper discusses the five core elements of the modernization program:

1. Automation of the main backbone channel system

2. Farm to backbone connections

3. Upgrading metering technologies

4. Water savings

5. Challenges of investing in modernizing irrigation assets and environmental flows simultaneously.

\section{INTRODUCTION AND BACKGROUND}

The Murray Darling Basin, highlighted in Figure 1 below, is the principal agricultural production area of Australia.

\footnotetext{
${ }^{1}$ Chief Executive Officer, Northern Victoria Irrigation Renewal Project (NVIRP), 461 Wyndham Street, Shepparton, Victoria, Australia 3630, murray.smith@nvirp.com.au
} 


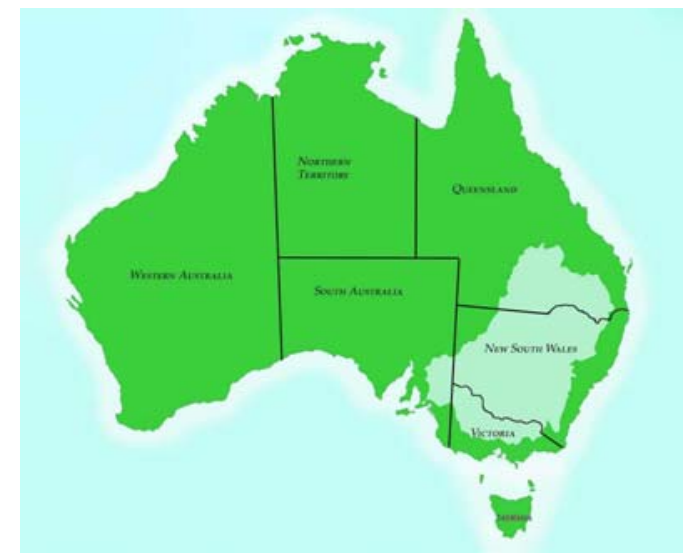

Figure 1. Murray Darling Basin

For the 2008-09 water year (June 2008 to May 2009) inflows to the major storages in the connected southern Murray Darling system were the third driest in 118 years of records (1,860 GL). This followed the seventh driest year in 2007-08 and the driest on record in 2006-07 (970 GL) ${ }^{\text {iii }}$. The long term annual average is 8,840 GL (excluding inflows from the Snowy system and Menindee Lakes). The consequences of these conditions are shown in volume storages as displayed in Figure 2.

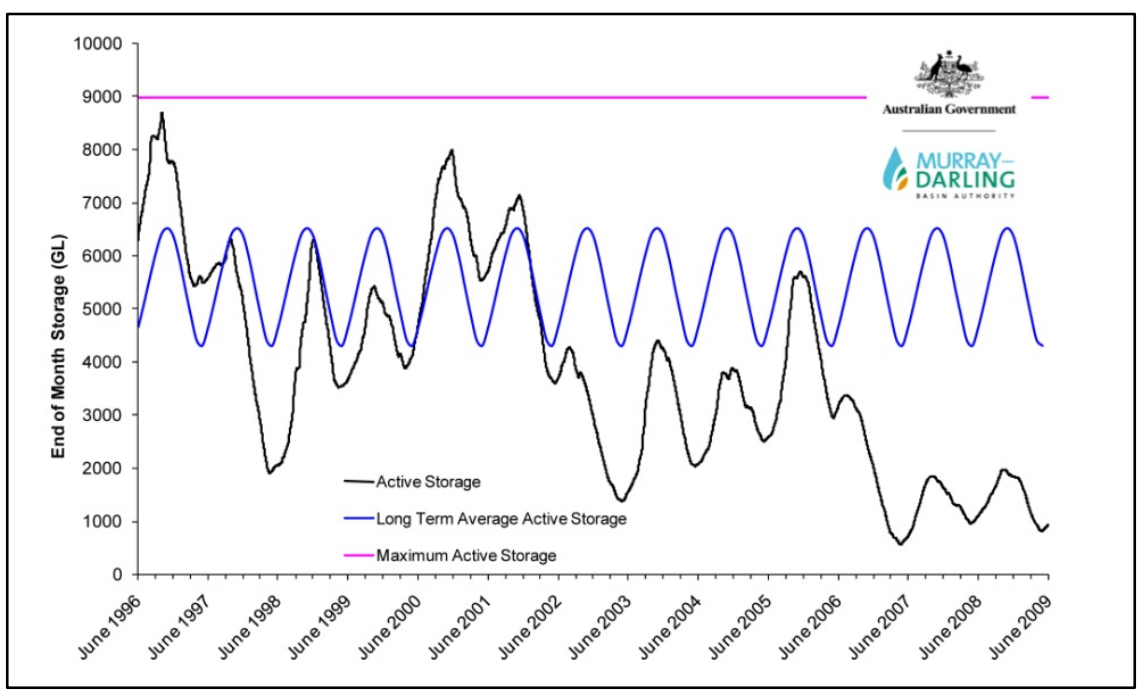

Figure 2. Murray Darling Basin Southern Connected system storages, June 1996 to May 2009

To address these and other climate related impacts, in 2004 the Victorian State Government (one of the four riparian states in the Murray-Darling Basin) formulated a long-term plan for water - Our Water Our Future. In June 2007, the Victorian Government announced Our Water Our Future - The Next Stage of the Government's Water Plan, a $\$ 4.9$ billion AUS investment in major water infrastructure, including a number of projects to enhance water supplies in the Victorian part of the southern Murray-Darling Basin. A key component of this initiative is the Northern Victoria 
Irrigation Renewal Project (NVIRP). NVIRP's function is to plan, design and deliver the program for modernizing the Goulburn Murray Irrigation District's (GMID) irrigation infrastructure which covers an area of $65,000 \mathrm{~km}^{2}$.

NVIRP is both the name of the project and the entity delivering the program. NVIRP works closely with the asset owner, Goulburn-Murray Water (G-MW) in rolling out its works program. NVIRP also works closely with other State Government Agencies, Shire Councils and industry and community groups.

The GMID is the single largest user of water in the Murray-Darling Basin, diverting on average 2,780 GL per annum. It is an integral part of Australia's major food producing region. The GMID supports 30 per cent of Victoria's gross value of agricultural production. The estimated value of farm gate irrigated agricultural commodity production from properties supplied through the GMID channel system was $\$ 1.4$ billion in 2005/06 from a state total of $\$ 8.5$ billion. Irrigated agricultural production in the GMID is diverse: however, a number of major industries account for the majority of the farm gate output. Dairy production is the largest single contributor to the regional economy, followed by livestock production, fruit production, fodder crops and vegetable production. The estimated farm gate value of agricultural production for the major commodities produced in the GMID channel districts is shown in Figure 3.

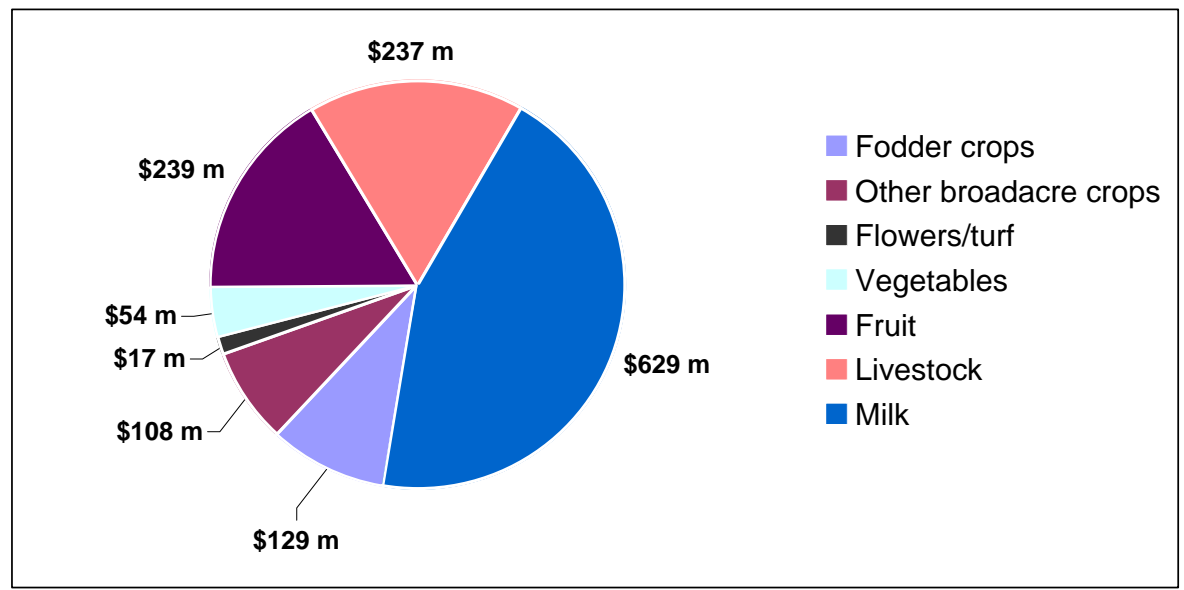

Figure 3. Local value of agricultural commodities produced - GMID 2005-06 ${ }^{\text {iv }}$

Much of the GMID channel system was built almost 100 years ago and significant water losses, equivalent to 30 per cent of the water in the GMID, are experienced as a result of system inefficiencies such as leakage, seepage and evaporation in channels, meter inaccuracies and outflows at the end of channels. 


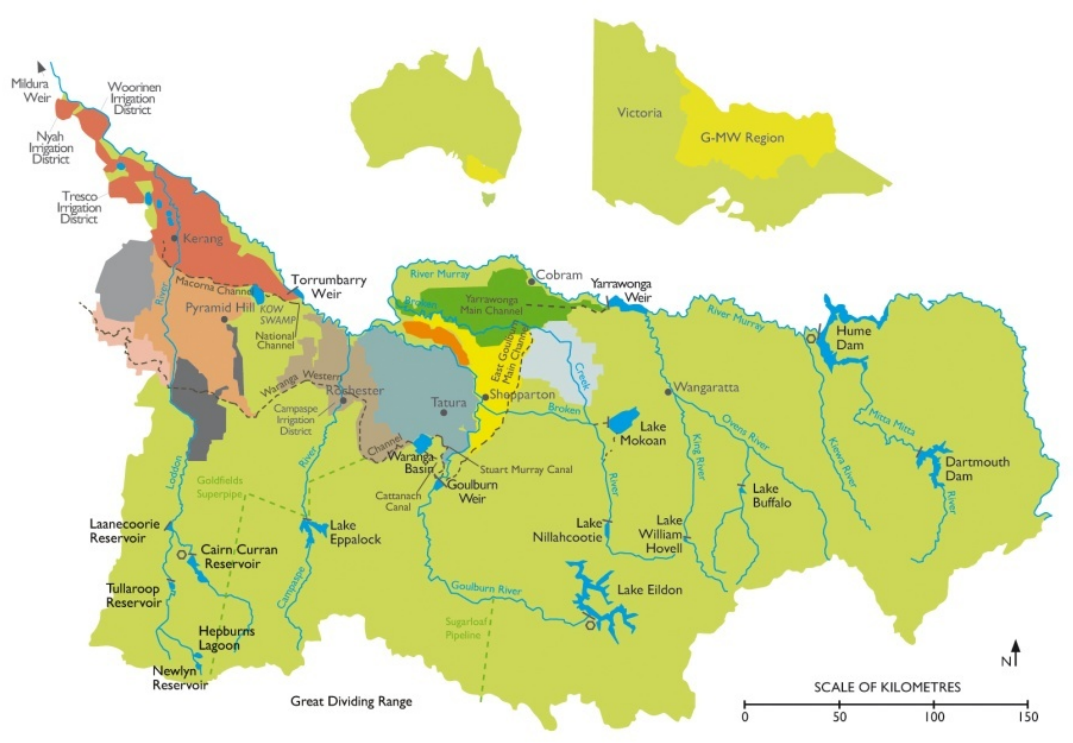

Figure 4. Map of the GMID in Victoria, Australia

The Project aims to recover water lost through leakage, seepage, evaporation and system inefficiencies via:

- channel lining and pipelining of channels

- $\quad$ automation of channels across the GMID

- metering rationalization and upgrades

- reconfiguration (i.e. decommissioning channels and realigning the historical layout of the irrigation channels).

Modernization aims to increase irrigation delivery efficiency from approximately 70 per cent to at least 85 per cent and effectively capture at least half of the current system losses. This project has drawn on experience from existing water savings projects in Victorian in the Goulburn system, the Macallister Irrigation District and in Coleambally in New South Wales.

Stage 1 of the NVIRP Project involves an investment of \$1 billion (AUS) to modernize infrastructure within 58,500 $\mathrm{km}^{2}$ of the GMID. Modernization of the GMID irrigation distribution system will:

- increase the standard of water delivery services, providing more uniform flow, increased supply to provide better control of water across surface irrigated land, shorter water ordering times and more efficient land use by removing redundant channels and structures

- lead to increased farm gate productivity and profitability and improved irrigation application efficiency, thereby assisting farmers with market competitiveness

- reduce system losses, allowing more water to be used for productive and environmental purposes. 
At a national level, the Australian Commonwealth Government Water for the Future program aims to secure the future of irrigation communities and improve river health in the Murray-Darling Basin. The program aims to provide funding to significant statebased water infrastructure projects, in order to address climate change and reduced water availability. Subject to due diligence and the delivery of half of the water savings gained as additional flows to the environment, the Commonwealth Government has committed to contributing 90 per cent of the total project costs for Stage 2 of the NVIRP project, up to a maximum funding amount of $\$ 1$ billion (AUS). Stage 2 will build upon Stage 1 by extending modernization works across the full extent of the GMID system.

The Commonwealth Government recognizes that Australia faces major challenges in ensuring sustainable water supply in the face of drying climate and rising demand for water. In response, the Australian Government's framework, Water for the Future (\$12.9 billion AUS over 10 years), provides national leadership in water reform for all Australians. Water for the Future is built on four key priorities:

- Taking action on climate change

- Using water wisely

- $\quad$ Securing water supplies

- $\quad$ Supporting healthy rivers. ${ }^{\mathrm{v}}$

Investment in Stage 2 of NVIRP is expected to generate up to an additional 200 GL of long term average annual water efficiency savings, to be shared equally between the Commonwealth Environmental Water Holder and GMID irrigators.

In addition, $\$ 3.1$ billion of the $\$ 12.9$ billion AUS has been committed to buying back water entitlement under the Commonwealth Government's program, Restoring the Balance in the Murray-Darling Basin.

\section{MODERNIZATION OF THE GMID}

NVIRP has three core objectives:

- to promote the sustained viability of the GMID as the Murray-Darling Basin's major food production area

- to create an irrigation supply system that meets world's best practice and maximizes its resilience in the face of climate change

- to generate water savings for productive use and enhance environmental flows. These core objectives are integrated and delivered through NVIRP's investment in the modernization of the supply system for the GMID.

\section{Defining and Automating the Channel Backbone}

Overall there are approximately 6,300 km of earthen channels in the GMID, which makes it Australia's largest irrigation channel network. Works associated with modernization of the larger carrier and trunk channels, which form the core 'backbone' from which farm connections will be based, include: 
- automation of channel control structures

- strategic measurement of off-takes and outfalls on the backbone

- rationalizing and upgrading regulating structures and other structures as required to avoid modernization costs and reduce ongoing operation and maintenance costs

- improving the standard of water supply service

- channel bank and bed remediation and lining where appropriate to generate water savings and restore the integrity of the system

- $\quad$ automated structures controlled by centralized predictive software - Total Channel Control ${ }^{\circledR}$ systems (TCC $\left.®\right)$. This in turn reduces system outfall and generates water savings.

Data captured through TCC ${ }^{\circledR}$ and additional pondage testing is improving the quality of the water balance, further informing NVIRP's investment decisions as works are better targeted at recovering water losses and service enhancement. To determine the extent of the existing channel system to be retained as the modernized backbone, a methodology has been developed that assesses a number of attributes relevant to the future of irrigation in the region (see Figure 4). These include:

- Channel capacity utilization as defined by Delivery Share

- Land suitability for sustainable irrigation

- Location of large water use businesses

- Location of Prime Development Zones (PDZ) (i.e. those areas with good soils and topography)

- Reconfiguration program outcomes and targeted outcomes

- Consultation with Goulburn-Murray Water area operations staff

- Consultation with customer Water Service Committee and Modernization Committee members.

The methodology recognizes that the concept of modernization affords the opportunity to analyze future infrastructure requirements against tailored water supply services. In the future, it is anticipated that water supply services will include gravity and pressure irrigation (with various levels of command), domestic and stock supplies and, in a small number of cases, no service (or removal of service). These services will most likely be provided by a blend of public (modernized backbone) and private infrastructure but will predominantly be private channels.

To ensure the objectives and principles of the NVIRP are met, it is necessary to reduce the extent of the backbone to cost effectively facilitate the desired outcomes of the connections component of NVIRP and fit within the project budget.

Following examination of accumulated Delivery Shares along each channel within the channel system, the channel cut off point using Delivery Shares is to be applied to those channels or sections of channel with greater than $20 \mathrm{ML} / \mathrm{d}^{\mathrm{vi}}$ accumulated Delivery Shares, which currently equates to the equivalent to about 2,000 ML/year usage (based on the 270-day irrigation season). 
To facilitate the determination of the extent of backbone a generic procedure has been developed and applied uniformly across the project footprint. This generic procedure is shown in the figure below.

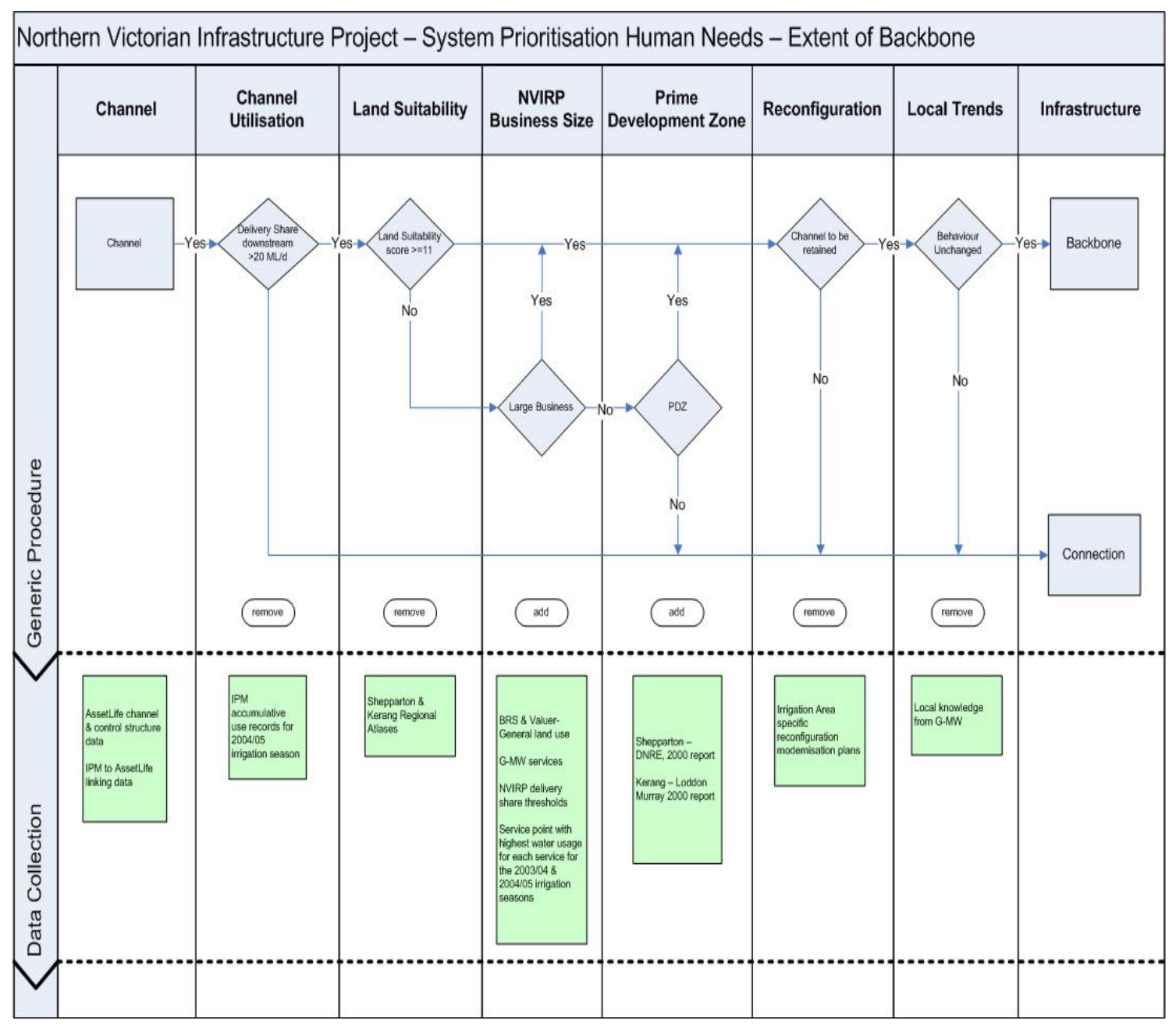

Figure 5. NVIRP - Decision Tree for Determining the Extent of the Modernized

Backbone

To reduce the risk of redundancy, the modernized backbone needs to supply more than one farm. Therefore, two large mixed farms were considered the smallest unit (to give the same service across the region), which meant a required minimum channel capacity to meet the needs in delivering approximately 2,000 ML of water entitlement per annum (i.e. $20 \mathrm{ML} / \mathrm{d}$ Delivery Shares). There is a balance between extending the backbone further and reducing the average distance farmers on spurs need to go to access the backbone. Taking the backbone into small channels means the system can not deliver fitfor purpose services such as water near-on-demand and constant flows during irrigation.

Delivery Shares provide an irrigator a claim to the channel capacity to have water delivered to land in an Irrigation District and a share of the available water flow in a delivery system. Delivery Shares are linked to land and stay with the property if the 
Water Share is traded away. Delivery Share may be traded to other landowners supplied from the same channel or to channel systems where capacity is available or relinquished.

To date approximately 2,900 $\mathrm{km}$ of the existing channel system has been defined as the backbone. Irrigators on the spur channels not included within the backbone will be targeted by the Connections Program which aims to remove public spur or distribution channels (i.e. those channels not included in the new Backbone) and enable the Backbone to be the prominent footprint in the GMID by:

- creating new direct connections to the backbone for those customers who are currently connected to spur channels

- relocating water supply points from spurs to the backbone

- removing water usage from spur channels

- removing spur channels from the public supply system.

Historically, some 60 per cent of the length of the irrigation supply system was comprised smaller spur channels. These generally provide a low level of service, and are leaky and costly to maintain.

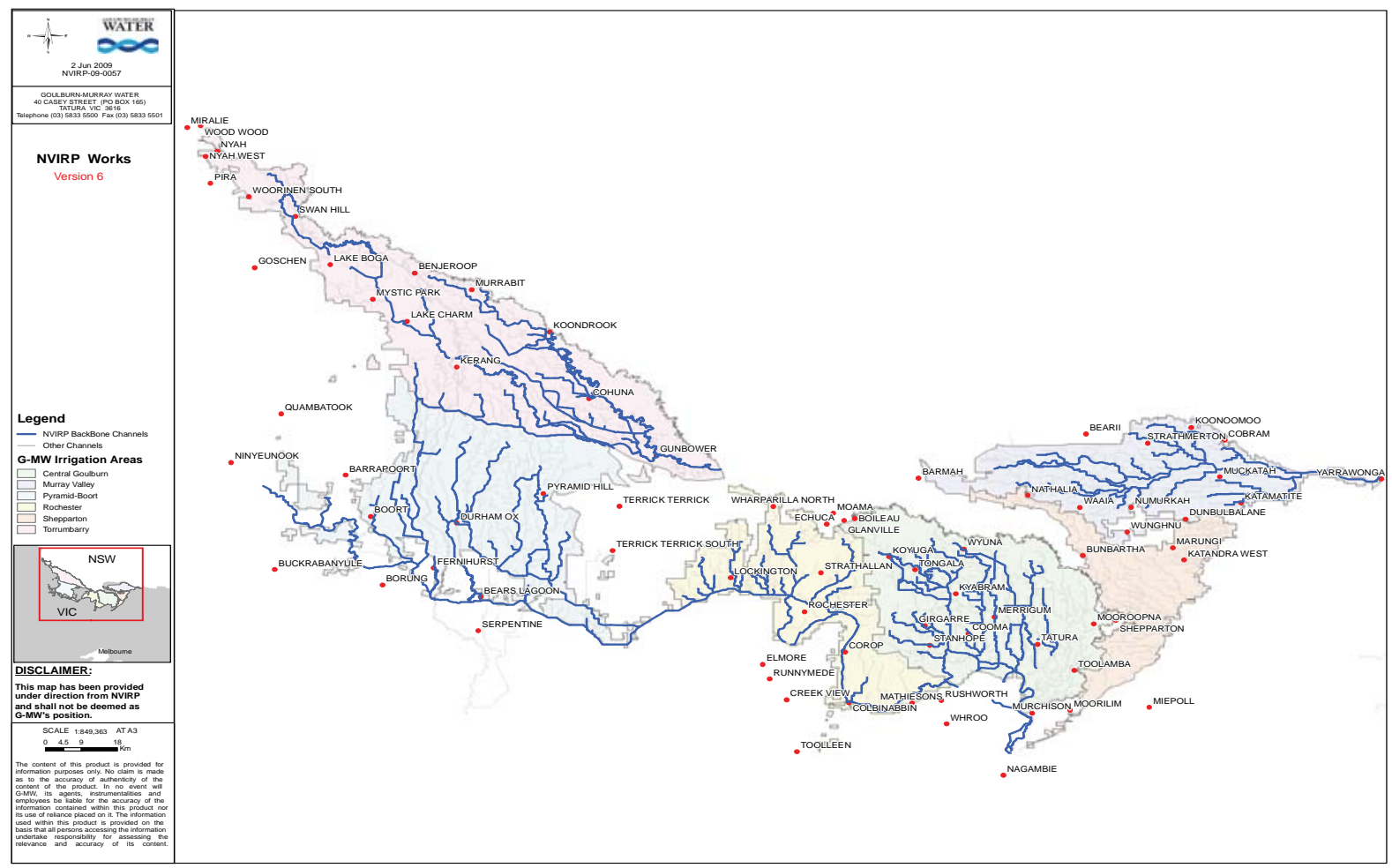

Figure 6. Backbone Channels

\section{Connections Program}

A key element of NVIRP is the Connections Program, which aims to generate in the order of 200 GL of long term average annual water savings and contribute to the delivery 
of a modernized irrigation system. This will be achieved by gaining landowner agreement to rationalize channels, transfer water Delivery Shares to the main backbone channels and reduce the number of service point connections to the backbone channel.

The main backbone channel comprises larger carrier and trunk channels, from which all service connections are to be based. Rationalization refers to making the system more efficient by concentrating connections on the backbone channels, instead of through a wide network of obsolete spur channels and infrastructure. Rationalization is also delivering a system that is affordable to customers.

Rationalizations are occurring to remove redundant infrastructure and create service points focused on accessing the main backbone channel. The Connections Program includes avoiding modernization costs by connecting properties to the backbone, rationalizing infrastructure and replacing or upgrading meters along the backbone. By connecting landowners to the backbone network of large modernized supply channels, the program can:

- develop and maximize rationalization opportunities, thus creating a cost-effective and affordable irrigation system through consideration of Whole of Life (Operations \& Maintenance) cost implications. This is described further in Goulburn-Murray Water's Impact of Modernization: Whole of Life Cost Analysis ${ }^{\text {vii }}$ report

- develop an incentive based payment offer that meets both the objectives of NVIRP and the landowner

- maximize connections from the backbone to improve levels of service

- help reach agreements for meter replacements on the backbone

- facilitate ongoing farm improvements

- generate water savings.

In essence, rationalization and connection opportunities involve the development of individual business cases and the offer of incentives to landowners through a negotiation process. Agreements are developed that meet the landholder's objectives whilst reducing the public irrigation supply network and associated costs to generate water savings.

Farm Irrigation Assessment (FIA) The FIA is a critical element of the Connections Program, delivered by Farm Designers engaged by NVIRP. The FIA process provides a fair assessment of on-farm connection costs, maximizes rationalization opportunities, informs landowners of their options and provides them with time to plan for change and make informed decisions.

The FIA process is also a methodical process whereby the Farm Designers work their way through a designated section of the channel system in a way that addresses avoided modernization opportunities that may exist and captures economies of scale and scope. It also helps assess connection opportunities for every landholder along a section of the channel system.

On-farm costs are incurred for any works that are required on-farm to reinstate the farm water delivery system, or ensure it continues to be operational, as a result of a change in the supply system servicing the property. To be eligible for on-farm cost incentives, the 
works must be necessary as a direct result of a new connection to the backbone, to avoid backbone modernization costs and/or the rationalization of spur channel infrastructure.

Incentives The objective of the incentive payments is to provide incentives to landholders to agree to the rationalization of infrastructure, reduce administration and internal audit costs, while ensuring a fair and transparent process that encourages on-farm investment, minimizes environmental risks and enhances regional development opportunities.

In essence, NVIRP is purchasing water savings, which results in reduced irrigation infrastructure and Whole of Life costs for the irrigation system whilst delivering on broader modernization objectives. To encourage on-farm changes, a portion of the incentive is withheld until all works have been completed as agreed.

Incentives are paid to individual landowners or groups of landowners to enable NVIRP to achieve its objectives under the Connections Program. There are three types of incentives available through NVIRP:

- Backbone Incentives - by rationalizing meter outlets and/or regulators on the backbone, avoided modernization costs and water savings are generated. This also reduces ongoing operation, maintenance and future renewal costs

- Connections Incentives - moving Delivery Share to the backbone results in water savings being generated as water delivery is metered through an accurate water meter

- Rationalization - decommissioning infrastructure results in water savings being generated and reduces ongoing operation, maintenance and future renewal costs.

Generally, a Connections Incentive involves the transfer of Delivery Share from an existing service point to a new/modernized service point location on the modernized backbone channel. This may also involve the privatization or rationalization of irrigation assets, including channels, culverts, regulators and other structures. Incentives are available for each kilometer (or part thereof) of channel removed (less direct project costs). The incentive packages are designed to encourage connections to the backbone as the highest priority. A key point of the incentive package is that the value that can be offered to a landholder is determined by the scale of the on-farm works required to reconnect an irrigation supply, not the value of the water savings an individual business case generates.

\section{Improved Metering of Supplies}

Currently water is delivered to Goulburn-Murray Water customers through approximately 24,500 discrete service points (or outlets). Approximately 65 per cent of these service points are metered using Dethridge Wheel meters. Dethridge Wheel meters have served the industry well over a long period of time; however they will not meet the new Australian National Metering Standards as with regard to field accuracy of $+/-5$ per cent. Goulburn-Murray Water in-situ meter testing has shown the potential for one Dethridge meter to deliver nearly 25 per cent more than the neighboring meter. Dethridge wheels also have inherent Occupational Health and Safety issues and are prone to tampering. 
Domestic and Stock small volume users account for 30\% of all service points. The NVIRP metering program aims to facilitate water management and accountability, detect unauthorized use and improve water savings. The ability to accurately measure water will also encourage improved on-farm water use efficiency and support improved off-farm water supply system efficiency. As part of the NVIRP implementation all service points on the backbone channels will be metered with accurate meters.

As part of its implementation process NVIRP will provide landowners with choice in terms of their:

- number of service points

- $\quad$ service point location

- distribution of Delivery Shares between service points

- on-farm infrastructure size

- design flow rates

- type of meter.

A number of service points installed over the last 50 plus years are no longer required due to farm amalgamations and the nature of farming changes. This trend is expected to accelerate. To minimize the cost of meter replacement and reduce the number of replacement meters that will not be fully utilised in the longer term, NVIRP is putting significant effort into service point rationalization/decommissioning. This effort is supported by a strong meter related communication strategy and by providing financial compensation and supporting the introduction of cost-reflective tariffs.

A large number of the new meters being installed have a range of enhancement features including remote operation for larger outlets, which can influence the performance of TCC $^{\circledR}$ and remote read for smaller outlets. Domestic, stock and other very small outlets will remain local read only. The level of enhancement is largely based on the impact the service point/outlet may have on service levels of other customers and the operation of the system delivery channels. The remote operate and remote read outlets also have the capacity to build in additional features such as automation of on-farm systems and irrigation scheduling technologies.

\section{WATER SAVINGS}

Water savings are being systematically generated as the project is rolled out. These savings are a combination of fixed and variable elements, with the variable elements largely linked to annual water right allocations. Installation of TCC $^{\circledR}$ is reducing outfall losses. Targeted channel lining is reducing both seepage and leakage losses. The Connections Program with the rationalization of entire channels and related structures is generating a range of savings including removing evaporation losses. Installing new service points with new meters that have no systematic measurement bias will create high durability water savings due to improved meter accuracy and improved engineering standards on gate seals and concrete cutoffs, which will reduce supply point leakage. 


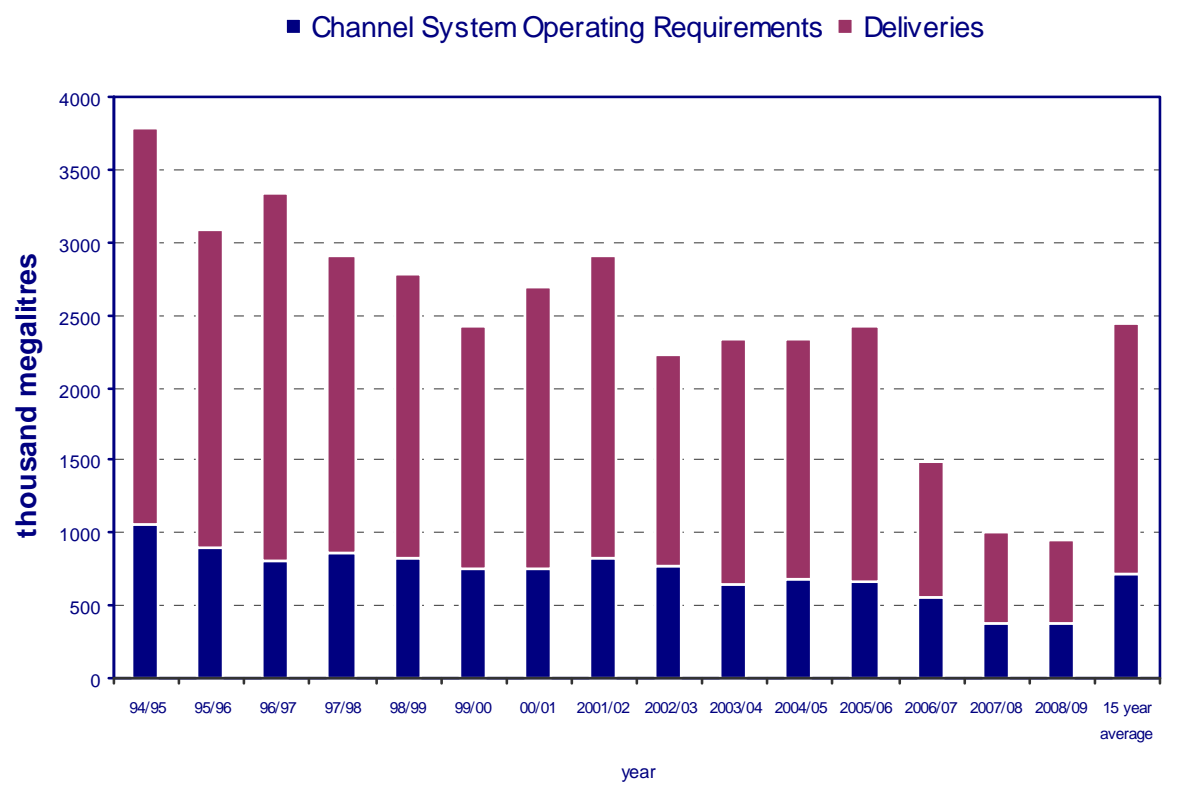

Figure 7. GMID Channel System deliveries and losses (1994/95 to 2007/08)

Water savings are effectively being generated by reducing system operating losses. Figure 7 highlights that whilst water deliveries have varied significantly over the past 15 years, system operation losses have been relatively stable. This is notwithstanding the last few years, where in response to drought some channels have not been operated at all while other have operated below design operating level in efforts to maximize what water is available.

The water savings generated will be independently audited at the end of the irrigation season in May. These savings will be shared with urban users in Melbourne, system irrigators and to benefit environmentally impacted wetlands and waterways. However, the Victorian Government's stance to take water saved from north of the State to the south has evoked a similar emotional outcry as has been seen in California.

Figure 8 below provides an overview of the annual water allocation process whereby system operating losses must be covered before customers can receive any allocation towards their water entitlement rights. By reducing system operating losses customers (including the environment) will receive more water earlier in the irrigation season than is currently the case. 


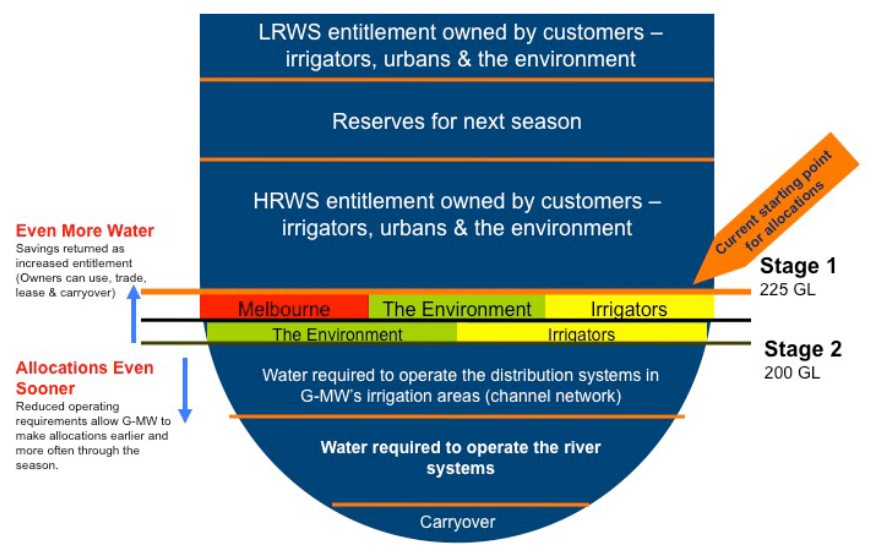

Figure 8. Delivering more water sooner through modernization LRWS = Low Reliability Water Share, HRWS = High Reliability Water Share

\section{SYNERGIES BETWEEN WATER PURCHASE AND INFRASTRUCTURE MODERNIZATION INVESTMENT}

The Commonwealth Government's Department of Environment, Water, Heritage and the Arts (DEWHA) is responsible for administering the Commonwealth's water rights or entitlements purchase/buyback scheme under its \$3.1 billion (AUS) program, Restoring the Balance in the Murray-Darling Basin. Water entitlements [acquired under this program] will be used to protect or restore environmental assets such as wetlands and streams $^{\text {viii }}$.This activity generally uses an open tender process as the principal mechanism of purchasing water entitlements. The very scale of purchases is creating significant distortions in the water market. This is evidenced by the average purchase price being paid by DEWHA against prices being paid in areas that do not have access with a price differential of approximately \$500 AUS/ML of entitlement.

As at September 2009 DEWHA's market activity commands 58 per cent of the total trade and up to 77 per cent in one key sector. This is liable to distort the market, particularly when that major purchaser is not driven by commercial pressures to validate a market value by reference to economic criteria - i.e. the ability to generate future revenue from irrigation from the use of that resource. The Victorian Government has had in place for some time a four per cent trading cap on the permanent sale of water entitlements out of irrigation areas. Whilst recognizing the importance of water trading markets, the capacity for communities to adapt to changing water environments was seen as critical.

\section{Untargeted Buyback}

Implementation of Buyback as a stand-alone untargeted program by itself has the potential to generate the following outputs and outcomes:

- a Swiss-cheese effect, with a scattering of de-watered properties across the landscape with no linkage to a coherent regional plan for future optimal land-use 
- an increase in the cost of future infrastructure reconfiguration as the remaining irrigation properties are located randomly across the region

- undermining of the value of the investment in modernized infrastructure when water is purchased directly from the new automated backbone

- higher unit costs for the remaining water users

- reduction in productivity where water is taken from highly productive soils ideally suited to irrigation with low environmental impacts, while leaving other less-desirable areas still heavily irrigated

- eroded community confidence in the process, who see little coherence or commitment to the bigger picture and longer term viability of the region.

\section{Targeted Buyback}

By contrast targeted purchase of water entitlement, combined with investment in infrastructure reconfiguration has the potential to generate significant synergies and support NVIRP's wider objectives. This targeting could yield the following outcomes:

- a reduction in demand on legacy spur channels. A Buyback target of 300GL would represent some $50 \%$ of the remaining water share located within spur channels

- buyback of water from spur channels helps promote system rationalization and will generate consequential water savings from closure of redundant channels and removal of older meters that under-record

- reduction in the costs of future connections. Where the water buyback is sourced from properties that are distant from the backbone this helps lower the average cost of new connections, as it reduces the number of high-cost, distant locations

- increased productivity on average across the irrigation district. Where the water is sourced from lower productivity areas and smaller properties Buyback helps promote overall productivity gains, as more of the water used on larger properties able to generate higher returns on better soils

- $\quad$ reduced environmental impacts. Where the water is sourced from areas with high environmental impact from salinity, then the purchase will help promote the sustainable future of the supply system by reducing demand in higher risk areas and increasing associated eco-system services

- greater social cohesion. Communities are willing to support water trading and buyback where they can see that it forms part of a coherent plan that takes account of associated implications for the economy, the environment and society.

For these synergies to be realized it will be important to target the application of Buyback to those locations that will yield multiple benefits. 


\section{Supporting Evidence from Commonwealth Scientific and Industrial Research Organization (CSIRO)}

Research by CSIRO confirms that integration of government water purchases with a wider reconfiguration exercise through 'spatial targeting' generates significant benefits. ix

With targeted buyback and land reconfiguration in just one of the six irrigation areas (Torrumbarry Irrigation Area) of the GMID, the value of ecosystem services was increased by up to $\$ 463.7 \mathrm{M}$ (AUS) against the base case through the generation of:

- 61GL of water for environmental flows

- sequestration of $10.6 \mathrm{M}$ tones of $\mathrm{CO}_{2} \mathrm{e} / \mathrm{yr}$ through reforestation

- 13 EC reduction on river salinity

- $24 \%$ increase in the value of agriculture production

Without a targeted approach to planning, the 20 per cent reduction in water for irrigation could result in a loss of $\$ 68.7 \mathrm{M}$ (AUS).

\section{Agreement between the Commonwealth and State Governments}

Under a new agreement between the Victorian State Government and the Australian Commonwealth Government it is proposed that some 460 GL could be purchased from the GMID through the Buyback program over a five year period. That is equivalent to $25 \%$ of the total available entitlement.

At the core of the cooperative model adopted by the State and Commonwealth Governments is the intent to maximize synergies between the program areas of both Governments such that:

- value for money investments are made in modernized irrigation infrastructure

- communities are provided time and resources to adapt to a changed water environment

- communities and industries are left more resilient to the impact of climate change.

As a result of the Water for the Environment Agreement between the Commonwealth and Victorian Governments, the Northern Victoria Irrigation Renewal Project (NVIRP) in conjunction with other stakeholders has established exemption criteria to allow permanent trade out of irrigation areas to the Commonwealth Government, irrespective of the 4 per cent Trading Cap. These criteria have at their core four elements.

Complements the NVIRP Modernization Program - results in a reductionin the public irrigation footprint (rationalizes assets and drives down the whole-of-life costs), generates water savings, improves the water delivery service and increases the affordability and security of irrigation for those that wish to remain in the industry into the future.

Generates sound land and water management outcomes - complements Land and Water Management Plans, generates beneficial environmental outcomes, and promotes sound irrigation practices. 
Is fair, transparent, and open - provides the irrigation community with the relevant information and the ability to seek support and advice prior to applying for an exemption and subsequent sale of water share to the Commonwealth.

Provides flexibility- provides the ability to adjust as circumstances change or key objective are achieved, and offers an avenue for all irrigation customers to participate if required.

Assessment Criteria include:

Irrigation suitability

Using soil type, salinity, environmental considerations, active floodplain, drainage provision, and salinity impacts to determine areas of the GMID that are unsuitable for irrigation.

Rural Land Use

Change

Areas where land use change is occurring e.g. urban expansion.

Distance from

Distance from the modernized backbone channel Backbone network is a key consideration in ensuring ongoing affordability of irrigation into the future.

\section{SUMMARY}

The integration and scheduling of the NVIRP program of works is assisting to inform ongoing infrastructure investment decisions as a result of an improved understanding of the system's water balance.

The Connections Program is playing an important role in helping secure the future of the GMID by generating water savings as part of the Northern Victoria Irrigation Renewal Project and delivering on core modernization objectives including:

- Strengthening the long term viability of the backbone channel system

- Improving on-farm irrigation systems leading to increased productivity

- Reducing Whole of Life costs of the irrigation system through rationalization of redundant assets and ensuring the affordability of the modernized system

- Encouraging further regional development and on-farm investment.

It is apparent from the landholder participation rate that the Connection Program is attractive. This is further supported by the fact that less than two per cent of offers have been rejected.

Investment in modernization is delivering more water sooner to both water users and the environment and is assisting manage the impacts of climate change. A targeted approach to water Buyback will provide a better value for money investment. It will also provide enhanced environmental and social outcomes which support more resilient and enduring communities. Whilst buyback is a necessary part of the Murray Darling Basin reforms, investment in infrastructure which reduces system losses increases water available for consumptive purposes and the environment. 
The joint funding arrangements facilitate the sharing of benefits across a generational project.

It is probable that the approach taken in Victoria Australia for the modernization of irrigation assets has applications elsewhere around the world with a purpose built entity able to draw together funding sources, engage with communities and key Government and other stakeholders.

\section{END NOTES}

${ }^{\mathrm{i}}$ www.mdba.gov.au

ii Australian Food Statistics 2008, Food Policy Section. Australian Government Department of Agriculture, Fisheries and Forestry - Agricultural production in 2008 valued at \$35.2 billion AUS.

iii http://www.dfat.gov.au

iv Australian Bureau of Statistics 2008 and RMCG July 2009

${ }^{\mathrm{v}}$ http://www.environment.gov.au/water/australia/index.html

${ }^{v i} 1 \mathrm{ML} / \mathrm{d}=1$ million liters per day or 0.811 acre feet per day

vii Impact of Modernization, Whole of Life Cost analysis, 12 June 2009

viii http://www.environment.gov.au/water/policy-programs/environment/index.html

${ }^{\text {ix }}$ Crossman et al CSIRO (2009), Reconfiguring an irrigation landscape to improve provision of ecosystem services 